\title{
Perfil físico-químico de aguardente durante envelhecimento em tonéis de carvalho
}

\author{
Chemical profile of aguardente - Brazilian sugar cane alcoholic drink - aged in oak casks
}

\author{
Mariana Branco de MIRANDA ${ }^{1}$, Nilo Gustavo Souza MARTINS ${ }^{1}$, \\ André Eduardo de Souza BELLUCO ${ }^{1}$, Jorge HORII ${ }^{1}$, André Ricardo ALCARDE ${ }^{1 *}$
}

\section{Resumo}

Avaliou-se por um período de 390 dias o perfil da composição química da aguardente sob envelhecimento em tonéis de carvalho de 20 L. O envelhecimento da aguardente em tonéis de madeira melhora a qualidade sensorial do destilado. As aguardentes envelhecidas foram analisadas aos 0, 76, 147, 228, 314 e 390 dias de armazenamento quanto às concentrações de etanol, acidez volátil, ésteres, aldeídos, furfural, álcoois superiores (n-propílico, isobutílico e isoamílicos), metanol, cobre, extrato seco, taninos e cor. Após os 390 dias de armazenamento, a aguardente apresentou maiores concentrações de acidez volátil, ésteres, aldeídos, furfural, álcoois superiores, congêneres, extrato seco e tanino. Sua coloração tornou-se amarelada. As concentrações de etanol e de metanol não se alteraram, e o teor de cobre apresentou ligeiro declínio. O envelhecimento da aguardente por 390 dias em tonéis de carvalho alterou a sua composição química, porém ela se manteve dentro de todos os padrões de qualidade estabelecidos pela legislação nacional em vigor.

Palavras-chave: composição; cachaça; maturação; madeiras.

\begin{abstract}
The chemical composition of aguardente - Brazilian sugar cane alcoholic drink - under aging during in $20 \mathrm{~L}$ oak casks was evaluated for 390 days. Aging sugar cane aguardente in wood casks improves the sensorial quality of the distillate. The concentrations of ethanol, volatile acidity, esters, aldehydes, furfural, higher alcohols (n-propylic, isobutylic and isoamylics), methanol, copper, dry extract, tannins, and color of the aged sugar cane aguardente were analysed at 0,76,147,228, 314, and 390 days of storage. After 390 days of aging the sugar cane aguardente presented higher concentrations of volatile acidity, esters, aldehydes, furfural, higher alcohols, congeners, dry extract, and tannin. Its color became golden. The concentrations of ethanol and methanol did not change and the copper content decreased slightly. The aging of the sugar cane aguardente in oak casks for 390 days changed the chemical composition of the distillate. However, the aged sugar cane aguardente met the quality standards established by Brazilian laws.
\end{abstract}

Keywords: composition; aguardente; maturation; woods.

\section{Introdução}

A produção de aguardente de cana e de cachaça no Brasil atinge 1,5 bilhões de litros anuais, representando $87 \%$ da produção nacional de bebidas alcoólicas destiladas. O consumo médio per capita do brasileiro é de 9,4 L/ano. O setor emprega cerca de 450 mil trabalhadores e movimenta internamente US\$ 1,0 bilhão por ano (BOZA; OETERRER, 1999).

A aguardente de cana possui uma graduação alcoólica de 38 a $54 \%$ em volume, a $20^{\circ} \mathrm{C}$. É obtida de destilado alcoólico simples de cana-de-açúcar (Saccharum officinarum L.) ou pela destilação do mosto fermentado de cana-de-açúcar, podendo ser adicionada de açúcares em até $6 \mathrm{~g} . \mathrm{L}^{-1}$. A aguardente de cana pode conter até $30 \mathrm{~g}$. $\mathrm{L}^{-1}$ de açúcares, devendo, porém, ter sua denominação acrescida da palavra "adoçada" (BRASIL, 2005).

A aguardente de cana envelhecida refere-se à bebida que contiver, no mínimo, 50\% de aguardente de cana envelhecida em recipiente de madeira apropriado, com capacidade máxima de $700 \mathrm{~L}$, por um período não inferior a um ano. A aguardente de cana Premium é o destilado $100 \%$ envelhecido em recipiente de madeira apropriado, com capacidade máxima de $700 \mathrm{~L}$, por um período mínimo de um ano. Já aguardente de cana extra premium é aquela $100 \%$ envelhecida em recipiente de madeira apropriado, com capacidade máxima de $700 \mathrm{~L}$, por um período mínimo de três anos (BRASIL, 2005).

Além dos seus componentes principais, água e etanol, a aguardente apresenta, ainda que em baixas concentrações, componentes secundários formados principalmente durante a fermentação alcoólica e selecionados pelo processo de destilação e pela etapa de maturação do destilado. Tais componentes pertencem às classes funcionais dos ácidos, ésteres, aldeídos e álcoois, e em proporções menores formam-se também cetonas, compostos fenólicos, aminas e mercaptanas (MAIA, 1994).

O envelhecimento da aguardente em tonéis de madeira promove diminuição significativa do sabor alcoólico e da agressividade da bebida, com simultâneo aumento da doçura e do sabor de madeira, proporcionando uma efetiva melhora sensorial do produto (CARDELLO; FARIA, 1999).

Recebido para publicação em 26/4/2007

Aceito para publicação em 17/7/2008 (002489)

Departamento de Agroindústria, Alimentos e Nutrição, Escola Superior de Agricultura Luiz de Queiroz - ESALQ, Universidade de São Paulo - USP, Av. Pádua Dias, 11, CP 9, CEP 13418-900, Piracicaba-SP, Brasil, E-mail: aralcard@esalq.usp.br

${ }^{*}$ A quem a correspondência deve ser enviada 
A mudança do aroma e do sabor da bebida maturada deve-se a alterações na composição e na concentração dos seus compostos, as quais são causadas por extração dos compostos da madeira; quebra de suas macromoléculas e extração dos seus produtos; reações entre os compostos do destilado e da madeira; reação entre os próprios extrativos da madeira; reação entre os próprios componentes do destilado; e evaporação dos compostos voláteis (MOSEDALE; PUECH, 1998).

Algumas substâncias podem ser consideradas referências no processo de envelhecimento. Durante a maturação de bebidas destiladas normalmente ocorre uma diminuição do $\mathrm{pH}$ e das concentrações de álcool metílico e de álcool etílico, enquanto que há um aumento da acidez, da cor e das concentrações de acetato de etila, de aldeído acético, de acetona e dos compostos fenólicos (taninos) (CARDELLO; FARIA, 1997; PUECH, 1983; SOUZA; DEL MASTRO, 2000).

No Brasil, a etapa de envelhecimento da aguardente é optativa, não sendo realizada sistematicamente devido ao tempo requerido pelo processo e aos custos introduzidos pelo armazenamento da bebida em tonéis por alguns anos. Porém, essa etapa é indispensável quando se deseja agregar qualidade e, conseqüentemente, valor a uma bebida destilada.

O objetivo deste trabalho foi monitorar a evolução da composição química da aguardente sob envelhecimento em tonéis de carvalho de $20 \mathrm{~L}$ por um período de 390 dias.

\section{Material e métodos}

A aguardente utilizada foi proveniente de uma destilação de $300 \mathrm{~L}$ de aguardente, realizada em setembro de 2006 na Destilaria Piloto do Departamento de Agroindústria, Alimentos e Nutrição da Escola Superior de Agricultura "Luiz de Queiroz" da Universidade de São Paulo. A variedade de cana-de-açúcar utilizada para a produção da aguardente foi a SP 83-2847, cultivada nas dependências do Departamento.

Amostras da aguardente, apresentando aproximadamente $43^{\circ} \mathrm{GL}$, foram envelhecidas em tonéis de carvalho de $20 \mathrm{~L}$, adquiridos no comércio local e confeccionados a partir de tonéis reaproveitados. Os tonéis permaneceram sob uma bancada e na posição horizontal durante todo o período de estudo. Para a execução das análises físico-químicas, as amostras foram retiradas dos tonéis com o auxílio de uma pipeta, através do batoque, localizado na parte superior. Como controle, $20 \mathrm{~L}$ da aguardente permaneceram armazenados em um recipiente de vidro durante todo o período do experimento.
Análises físico-químicas foram realizadas aos 0, 76, 147, 228, 314 e 390 dias de armazenamento. As análises de grau alcoólico, acidez volátil, extrato seco e furfural seguiram as metodologias oficiais descritas em Brasil (1986). A determinação de cobre seguiu a metodologia do Instituto Adolfo Lutz (PREGNOLATO; PREGNOLATO, 1985). A análise de tanino seguiu o método da AOAC (1995) e a cor foi analisada através de espectrofotômetro modelo Coleman Jr. III, seguindo metodologia descrita por Silva Júnior (1999). As análises cromatográficas de aldeídos, ésteres, álcoois superiores (n-propílico, álcool isobutílico e álcoois isoamílicos) e álcool metílico foram efetuadas utilizando-se um cromatógrafo gasoso CG-037, equipado com uma coluna empacotada PAAC 3334-CG e um detector de ionização de chama (FID). Como gás de arraste utilizou-se $\mathrm{H}_{2}$, com vazão de $30 \mathrm{~mL} /$ minuto. A temperatura do injetor foi programada para $170{ }^{\circ} \mathrm{C}$. A programação da temperatura da coluna foi isotérmica a $94^{\circ} \mathrm{C}$. A temperatura do detector foi programada para $225^{\circ} \mathrm{C}$ (BOZA, 1996). Foram efetuadas três injeções, de $3 \mu \mathrm{L}$ cada, para cada amostra. Utilizou-se padrão externo para a determinação dos tempos de retenção e da concentração dos componentes (Figura 1 e Tabela 1).

O delineamento estatístico utilizado foi inteiramente casualisado. Os tratamentos referiram-se aos tempos de armazenamento da aguardente em três tonéis de carvalho, os quais foram considerados como as três repetições do experimento. Com o auxílio do programa estatístico SAS (1996) foram aplicados análise de variância (ANOVA) e teste de médias de Tukey a 5\% de significância (PIMENTEL-GOMES; GARCIA, 2002).

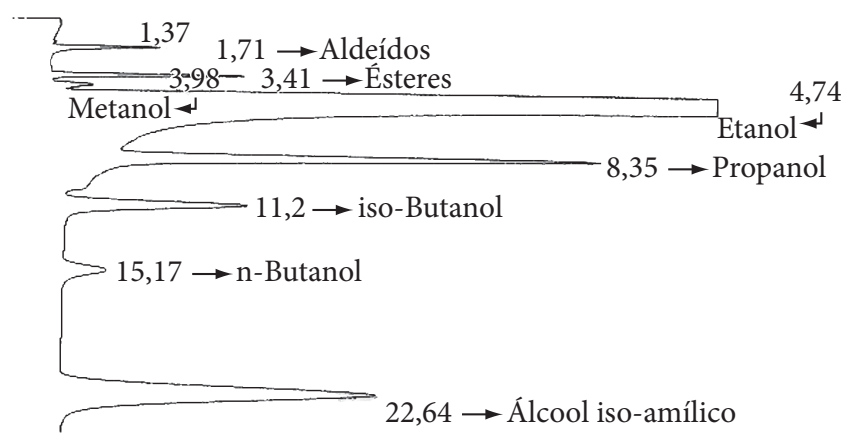

Figura 1. Cromatograma do padrão externo com a identificação do pico referente a cada composto analisado.

Tabela 1. Dados de calibração do analisador do cromatógrafo.

\begin{tabular}{lcccc}
\hline \multicolumn{1}{c}{ Componentes } & Tempo de retenção (minutos) & Concentração $(\mathrm{C})\left(\mathrm{mg} .100 \mathrm{~mL}^{-1}\right)$ & Área do pico $(\mathrm{A})$ & Relação C/A \\
\hline Aldeídos & 1,71 & 7,88 & 3669 & 0,0021477 \\
Ésteres & 3,41 & 8,97 & 5863 & 0,0015299 \\
Metanol & 3,98 & 3,96 & 2140 & 0,0018505 \\
Propanol & 8,35 & 28,12 & 35940 & 0,0007824 \\
iso-Butanol & 11,2 & 12,03 & 17047 & 0,0007056 \\
n-Butanol & 15,17 & 4,05 & 5295 & 0,0007647 \\
Álcool iso-amílico & 22,64 & 40,65 & 58292 & 0,0006973 \\
\hline
\end{tabular}




\section{Resultados e discussão}

Ao final dos 390 dias a aguardente armazenada no recipiente de vidro apresentou a mesma composição físico-química inicial (Tabela 2), com exceção para a concentração de ésteres, a qual aumentou $57 \%$ durante o período de armazenamento. Isso ocorreu porque as reações de esterificação, que ocorrem entre compostos ácidos e álcoois do próprio destilado, também ocorrem em recipientes inertes, porém de forma mais lenta, pois não têm a participação das reações intrínsecas ao processo de envelhecimento em madeira.

Quanto à aguardente armazenada em madeira, o seu grau alcoólico apresentou tendência de aumento ao longo do período de envelhecimento, porém esse aumento não foi estatisticamente significativo. A acidez volátil, o extrato seco, os álcoois superiores, os congêneres, a cor e os componentes ésteres, aldeídos, furfural e tanino aumentaram suas concentrações com o avanço do período de envelhecimento. A concentração de metanol não sofreu variação ao longo do período de envelhecimento. O teor de cobre das aguardentes apresentou ligeiro declínio com o envelhecimento do destilado (Tabela 2).

O grau alcoólico de uma aguardente armazenada em tonéis de madeira pode sofrer oscilações em função da umidade relativa e da temperatura ambiente. No Brasil são comuns perdas de água e de álcool em torno de 3 a $4 \%$ ao ano, seja pela qualidade dos tonéis utilizados, seja pela idade das madeiras em uso. Em ambiente de baixa umidade relativa, a perda de água é favorecida, enquanto que a alta umidade favorece a perda de álcool através dos tonéis (NICOL, 2003). No presente estudo os resultados obtidos ao longo das cinco amostragens no período de 390 dias de envelhecimento não mostraram diferença estatística significativa. No entanto, observa-se uma tendência de aumento do grau alcoólico da aguardente ao longo do envelhecimento, mostrando que a evaporação de água do destilado foi maior que a de etanol durante esse período.
A acidez volátil da aguardente aumentou progressivamente ao longo do período de envelhecimento, sendo que ao seu final a aguardente apresentou 83,14 mg de ácido acético $100 \mathrm{~mL}^{-1}$ etanol puro, contra um valor inicial de $8,17 \mathrm{mg}$ de ácido acético $100 \mathrm{~mL}^{-1}$ etanol puro. Esse aumento se deve à reação de oxidação do etanol, a qual contribui para a formação de acetaldeído, o qual, por sua vez, conduz à formação de ácido acético (REAZIN, 1981; LITCHEV, 1989). Além disso, alguns compostos oriundos da madeira, tais como ácidos orgânicos não voláteis, componentes secundários, taninos e compostos fenólicos, favorecem o aumento da acidez da aguardente em envelhecimento. A legislação mantém elevado o limite máximo de acidez volátil visando proteger a aguardente envelhecida, cuja acidez sempre aumenta com o decorrer do período de envelhecimento. Desse modo, uma aguardente de baixa acidez inicial pode revelar seu grau de maturação pelo aumento da acidez volátil. Isso, todavia, não desqualifica o produto no aspecto sensorial pelo conjunto agradável que forma com outros componentes.

A aguardente envelhecida apresentou maior concentração de ésteres, pois, além das reações de esterificação entre os álcoois e os ácidos da bebida, os ésteres são um dos principais compostos extraídos da madeira pelos destilados. Os ésteres são produzidos durante a fermentação pelas leveduras e também durante o envelhecimento pela esterificação de ácidos graxos com etanol, sendo o acetato de etila o componente majoritário deste grupo (FARIA et al., 2003) e responsável pelo odor agradável das bebidas envelhecidas (LITCHEV, 1989). A concentração de ésteres da aguardente praticamente triplicou durante o período de envelhecimento.

O teor de aldeídos da aguardente aumentou 125\% ao longo dos 390 dias de envelhecimento do destilado. Uma das reações químicas mais importantes durante a maturação e que altera os componentes do destilado é a oxidação e formação de acetal. Exemplos de oxidação são a formação de acetaldeído e ácido

Tabela 2. Perfil físico-químico da aguardente ao longo do envelhecimento e ao final do armazenamento em recipiente de vidro.

\begin{tabular}{|c|c|c|c|c|c|c|c|}
\hline Componentes & Inicial & 76 dias & 147 dias & 228 dias & 314 dias & $\begin{array}{c}390 \text { dias } \\
\text { (madeira) }\end{array}$ & $\begin{array}{c}390 \text { dias } \\
\text { (vidro) }\end{array}$ \\
\hline Acidez volátil (mg ácido acético $100 \mathrm{~mL}^{-1}$ etanol anidro) & $8,17^{\mathrm{a}}$ & $30,86^{\mathrm{b}}$ & $38,94^{\mathrm{b}}$ & $57,77^{\mathrm{c}}$ & $64,96^{\mathrm{c}}$ & $83,14^{\mathrm{d}}$ & $8,72^{\mathrm{a}}$ \\
\hline Aldeídos (mg aldeído acético $100 . \mathrm{mL}^{-1}$ etanol anidro) & $12,63^{\mathrm{a}}$ & $20,80^{\mathrm{b}}$ & $22,86^{\mathrm{b}}$ & $22,24^{\mathrm{b}}$ & $25,78^{\mathrm{bc}}$ & $28,41^{\mathrm{c}}$ & $14,79^{\mathrm{ab}}$ \\
\hline Furfural (mg.100 mL $\mathrm{mL}^{-1}$ etanol anidro) & $0,02^{\mathrm{a}}$ & $0,66^{\mathrm{b}}$ & $0,71^{\mathrm{b}}$ & $0,94^{\mathrm{c}}$ & $0,96^{\mathrm{c}}$ & $1,14^{\mathrm{d}}$ & $0,02^{\mathrm{a}}$ \\
\hline Álcool n-propílico (mg.100 mL $\mathrm{m}^{-1}$ etanol anidro) & $46,72^{\mathrm{a}}$ & $52,58^{\mathrm{b}}$ & $42,99^{\mathrm{a}}$ & $43,18^{\mathrm{a}}$ & $43,92^{\mathrm{a}}$ & $46,52^{\mathrm{a}}$ & $44,12^{\mathrm{a}}$ \\
\hline Álcoois superiores (mg.100 mL $\mathrm{m}^{-1}$ etanol anidro) & $312,30^{\mathrm{a}}$ & $333,80^{\mathrm{ab}}$ & $304,98^{\mathrm{a}}$ & $309,29^{\mathrm{a}}$ & $321,76^{\mathrm{a}}$ & $354,29^{\mathrm{b}}$ & $297,95^{\mathrm{a}}$ \\
\hline Congêneres (mg. $100 \mathrm{~mL}^{-1}$ etanol anidro) & $340,62^{\mathrm{a}}$ & $399,19^{\mathrm{b}}$ & $380,39^{\mathrm{ab}}$ & $404,12^{\mathrm{b}}$ & $433,50^{c}$ & $486,00^{\mathrm{d}}$ & $330,28^{\mathrm{a}}$ \\
\hline Álcool metílico (mg.100 mL $\mathrm{mL}^{-1}$ etanol anidro) & $6,48^{\mathrm{a}}$ & $6,95^{\mathrm{a}}$ & $6,22^{\mathrm{a}}$ & $6,93^{\mathrm{a}}$ & $6,93^{\mathrm{a}}$ & $6,83^{\mathrm{a}}$ & $6,30^{\mathrm{a}}$ \\
\hline Cobre $\left(\mathrm{mg} . \mathrm{L}^{-1}\right)$ & $2,44^{\mathrm{a}}$ & $1,98^{\mathrm{ab}}$ & $1,86^{\mathrm{b}}$ & $1,86^{\mathrm{b}}$ & $1,86^{\mathrm{b}}$ & $1,86^{\mathrm{b}}$ & $2,42^{\mathrm{a}}$ \\
\hline
\end{tabular}

Cada valor corresponde à média das três repetições e das três análises efetuadas para cada repetição. A mesma letra na mesma linha significa que não existe diferença estatística a $5 \%$ de significância pelo teste de Tukey. 
acético a partir do álcool etílico (REAZIN, 1981) e a formação de dimetilsulfóxido a partir de dimetilsulfeto (PIGGOTT; CONNER, 2003). Os equilíbrios entre acetal e acetaldeído são estabelecidos também para muitos aldeídos e são particularmente importantes para um aroma específico, pois aldeídos freqüentemente têm odor desagradável e pungente, enquanto os acetais são agradáveis e frutados (PIGGOTT; CONNER, 2003). $\mathrm{O}$ acetaldeído tem características de odor reportadas como "refrescante", "frutado" e "verde", contribuindo assim para o aroma final de aguardente, tanto pela redução do odor pungente desse aldeído majoritário na bebida, quanto pelo provimento das características de aroma citadas (NÓBREGA, 2003). O equilíbrio entre aldeídos livres, hemi-acetal e acetal é influenciado pelo pH e a concentração de álcool etílico (PIGGOTT; CONNER, 2003) e também pelo tipo de madeira do tonel.

$\mathrm{O}$ teor de furfural da aguardente aumentou durante o envelhecimento, provavelmente devido à degradação de pentoses da madeira do tonel, conforme citado por Egorov e Rodopulo (1994). A Instrução Normativa ${ }^{\circ} 13$ (BRASIL, 2005) considera separadamente furfural e hidroximetilfurfural, sendo mantido o teor máximo conjunto de $5 \mathrm{mg} .100 \mathrm{~mL}^{-1}$ de álcool anidro. No processo de produção esses compostos são formados principalmente durante a destilação do vinho, surgindo predominantemente como produto de cauda em alambiques, dependendo do tipo de aquecimento (FARIA et al., 2003).

Os álcoois superiores foram analisados separadamente, como isobutílico, isoamílicos e n-propílico, através de análise cromatográfica já seguindo a metodologia exigida pela Instrução Normativa $n^{\circ} 13$ (BRASIL, 2005). Foi observado um ligeiro acréscimo no teor de álcoois superiores em função do tempo de envelhecimento. $\mathrm{O}$ acréscimo médio na concentração de álcoois superiores ao longo dos 390 dias de envelhecimento foi de aproximadamente $13 \%$, sendo que o álcool isobutílico apresentou um acréscimo de $12 \%$ e os isoamílicos de $18 \%$ no mesmo período. A concentração do álcool n-propílico da aguardente praticamente não se alterou durante o período de envelhecimento do destilado. Os álcoois superiores são produtos metabólicos decorrentes do crescimento das leveduras e do aproveitamento de aminoácidos como fonte de nutrientes amoniacais. Sua formação é também influenciada pelas condições do meio de fermentação, da quantidade e viabilidade do inóculo, da temperatura e do teor alcoólico final do vinho. Dependendo do equipamento e do processo de destilação, o teor no produto final pode variar bastante, tendendo a aumentar em até oito vezes o seu teor no destilado em comparação ao do vinho (LÉAUTÉ, 1990).

O coeficiente de congêneres (componentes voláteis "não álcool") é a soma de acidez volátil, aldeídos, ésteres, álcoois superiores e furfural. Como esses componentes separadamente tiveram suas concentrações aumentadas durante o período de envelhecimento, conseqüentemente, o coeficiente de congêneres também aumentou no decorrer do envelhecimento. Esse aumento foi de aproximadamente $43 \%$ ao longo dos 390 dias em que a aguardente permaneceu nos tonéis de carvalho.

A aguardente utilizada nesse trabalho apresentou uma média de $6 \mathrm{mg}$ de álcool metílico por $100 \mathrm{~mL}$ de álcool anidro e este valor não sofreu alteração significativa ao longo do período de envelhecimento. O álcool metílico em destilados tem origem na hidrólise de matérias pécticas. Como o teor de matérias pécticas em cana-de-açúcar é baixo, o teor de álcool metílico em seus destilados também é sempre baixo.

O teor de cobre da aguardente diminuiu durante o período de envelhecimento. Os tonéis podem ter absorvido ou adsorvido o elemento cobre. Ainda, compostos fenólicos como taninos podem ter reagido com o cobre produzindo mais cor, pois os tratamentos que apresentaram menor transmitância e, portanto, maior intensidade de cor, também apresentaram menores teores médios de cobre e maiores teores médios de tanino.

$\mathrm{O}$ teor de extrato seco da aguardente aumentou com o período de envelhecimento. Durante o envelhecimento o aumento do teor de extrato seco na aguardente ocorre devido à degradação da lignina pelo etanol em compostos aromáticos como a vanilina, siringaldeído, coniferaldeído e sinapaldeído. Além da extração destes compostos pelo álcool etílico, ocorrem ainda alterações na lignina em decorrência de oxidações e etanólise, as quais determinam denominações como "vanila", "adocicado" e "amadeirado" no destilado (PIGGOTT; CONNER, 2003).

A coloração da aguardente ao longo do período de envelhecimento tornou-se amarelada, devido à extração de compostos, principalmente taninos, e suas reações de oxidação, que segundo Singleton (1995), são os maiores responsáveis pelo progressivo escurecimento ou intensificação da cor amarelo-alaranjado em bebidas sob maturação em madeiras.

Houve um aumento na concentração de taninos da aguardente, principalmente nos primeiros 5 meses do período de envelhecimento. Nos primeiros 5 meses a concentração de taninos da aguardente passou de $0,65 \mathrm{mg} \cdot 100 \mathrm{~mL}^{-1}$ para $60,79 \mathrm{mg} \cdot 100 \mathrm{~mL}^{-1}$. No $13^{\circ}$ mês de envelhecimento a aguardente apresentou 80,91 mg.100 mL $\mathrm{mL}^{-1}$ de taninos. Assim, 75\% do aumento total da concentração de taninos da aguardente em envelhecimento ocorreu nos primeiros 5 meses. O restante ocorreu do $5^{\circ}$ ao $13^{\circ}$ mês do período de envelhecimento. Quanto à extração de taninos durante o envelhecimento da aguardente, deve ser considerada a razão superfície/volume. Tonéis de menor capacidade têm maiores relações superfície/volume e, conseqüentemente, resultam em maior rapidez de extração de componentes, mas também maiores taxas de evaporação de álcool etílico e de água.

Para uma mesma madeira e um mesmo histórico, em tonéis menores são esperadas produções maiores de extratos e envelhecimento de destilados em um período de tempo mais curto (PIGGOTT; CONNER, 2003). Segundo Mendes, Mori e Trugilho (2002), a aguardente sob envelhecimento em madeira torna-se amarelada, de paladar mais suave e tem a sensação desidratante do etanol atenuada devido à extração progressiva dos compostos fenólicos da madeira que confecciona o tonel.

Ao final do período de envelhecimento a aguardente continuou dentro dos padrões de qualidade estabelecidos pela Instrução Normativa n ${ }^{\circ} 13$ de 30 de junho de 2005 (BRASIL, 2005) (Tabela 3).

Os resultados desta pesquisa concordam com os obtidos por Parazzi et al. (2008), os quais estudaram as principais alterações 
Tabela 3. Características físicas e químicas para a aguardente de cana-de-açúcar estabelecidas pela legislação brasileira e composição das aguardentes desse experimento ao final do período de envelhecimento ou do armazenamento em vidro.

\begin{tabular}{|c|c|c|c|}
\hline Componentes & $\begin{array}{c}\text { Limites da legislação } \\
\text { (BRASIL, 2005) }\end{array}$ & $\begin{array}{c}\text { Aguardente envelhecida } \\
\text { em madeira }\end{array}$ & $\begin{array}{c}\text { Aguardente armazenada } \\
\text { em vidro }\end{array}$ \\
\hline Acidez volátil (mg ácido acético $100 \mathrm{~mL}^{-1}$ álcool anidro) & máx 150 & 83,14 & 8,72 \\
\hline Aldeídos (mg aldeído acético $100 \mathrm{~mL}^{-1}$ álcool anidro) & máx 30 & 28,41 & 14,79 \\
\hline Furfural + Hidroximetilfurfural (mg.100 mL $\mathrm{mL}^{-1}$ álcool anidro) & máx 5 & 1,14 & 0,02 \\
\hline Álcoois superiores (mg.100 mL $\mathrm{mL}^{-1}$ álcool anidro)* & máx 360 & 354,29 & 297,95 \\
\hline Álcool metílico (mg.100 mL $\mathrm{mL}^{-1}$ álcool anidro) & máx 20 & 6,83 & 6,30 \\
\hline Cobre $\left(\mathrm{mg} . \mathrm{L}^{-1}\right)$ & máx 5 & 1,86 & 2,42 \\
\hline Extrato seco (g.L $\left.\mathrm{L}^{-1}\right)$ & máx 6 & 1,76 & 0,10 \\
\hline
\end{tabular}

*Álcoois superiores $=$ (isobutílico + isoamílicos $+\mathrm{n}$-propílico $) ; \mathrm{e}^{\star *}$ Congêneres $=$ (acidez volátil + ésteres + aldeídos + furfural/hidroximetilfurfural + álcoois superiores $)$.

na composição química da aguardente de cana-de-açúcar envelhecida por 36 meses em tonéis de carvalho. Com o decorrer do período de envelhecimento observou-se aumento da acidez da bebida e das concentrações de ésteres, aldeídos, álcool isoamílico e compostos fenólicos totais. O teor alcoólico da aguardente e as concentrações dos álcoois metílico, n-propílico e isobutílico não apresentaram variação significativa ao longo do período de envelhecimento.

\section{Conclusões}

O envelhecimento da aguardente em tonéis de carvalho alterou a sua composição química, porém ela se manteve dentro de todos os padrões de qualidade estabelecidos pela legislação nacional em vigor. Após os 390 dias de armazenamento, a aguardente apresentou maiores concentrações de acidez volátil, ésteres, aldeídos, furfural, álcoois superiores, congêneres, extrato seco e tanino. A coloração da aguardente tornou-se amarelada. As concentrações de etanol e de metanol não se alteraram e o teor de cobre apresentou ligeiro declínio.

\section{Agradecimentos}

Os autores agradecem o Auxílio Pesquisa concedido pela FAPESP (processo nº 02/03921-5) para a execução do projeto.

\section{Referências bibliográficas}

AOAC - Association of Official Analytical Chemists. Official methods of analysis of the association of official analytical chemists. 16 ed. Washington, 1995. v. 2.

BOZA, Y. E. A. G. Influência da condução da destilação sobre a composição e a qualidade sensorial da aguardente de cana. Piracicaba, 1996. 143 p. Dissertação (Mestrado), Escola Superior de Agricultura "Luiz de Queiroz", Universidade de São Paulo.

BOZA, Y. E. A. G.; OETTERER, M. Envelhecimento de aguardente de cana. Boletim da Sociedade Brasileira de Ciência e Tecnologia de Alimentos, v. 33, n. 1, p. 8-15, 1999.

BRASIL. Leis, decretos, etc. Portaria n. 076, de 27 de novembro de 1986. Diário Oficial da União, Brasília, 03 de dezembro de 1986.

. Leis, decretos, etc. Instrução Normativa n. 13, de 29 de junho de 2005. Diário Oficial da União, Brasília, 30 de junho de 2005.
CARDELLO, H. M. A. B.; FARIA, J. B. Modificações físico-químicas e sensoriais de cachaça de cana durante o envelhecimento em tonel de carvalho (Quercus alba L.). Boletim do Centro de Pesquisa e Processamento de Alimentos, v. 15, n. 2, p. 87-100, 1997.

CARDELlO, H. M. A. B.; FARIA, J. B. Análise tempo-intensidade de características sensoriais de cachaça de cana durante o envelhecimento em tonel de carvalho (Quercus sp.). Boletim da Sociedade Brasileira de Ciência e Tecnologia de Alimentos, v. 33, n. 1, p. 27-34, 1999.

EGOROV, I. A.; RODOPULO, A. K. Investigation of aroma-forming substances In cognac spirits In their aging process. Applied Biochemistry and Microbiology, v. 30, n. 4-5, p. 539-542, 1994.

FARIA, J. B. et al. Cachaça, Pisco e Tequila. In: LEA, A. G. H.; PIGGOTT, J. R. (Eds.).Fermented beverage production. 2 ed. New York: Klumer Academic/Plenum Publishers, 2003. cap. 15, p. 335-363.

LÉAUTÉ, R. Distillation in alambic. American Journal of Enology and Viticulture, v. 41, n. 1, p. 90-103, 1990.

LITCHEV, V. Influence of oxidation process on the development of the taste and flavor of wine distilates. American Journal of Enology and Viticulture, v. 40, n. 1, p. 31-35, 1989.

MAIA, A. B. Componentes secundários da aguardente. STAB. Açúcar, Álcool e Subprodutos, v. 12, n. 2, p. 29-39, 1994.

MENDES, L. M.; MORI, F. A.; TRUGILHO, P. F. Potencial da madeira de agregar valor à cachaça de alambique. Informe Agropecuário, v. 23, n. 213 , p. $52-58,2002$.

MOSEDALE, J. R.; PUECH, J. L. Wood maturation of distilled beverages. Trends in Food Science \& Technology, v. 9, n. 3, p. 95-101, 1998.

NICOL, D. A. Rum. In: LEA, A. G. H.; PIGGOTT, J. R. (Ed.). Fermented beverage production. 2 ed. New York: Klumer Academic/Plenum Publishers, 2003. cap.12, p. 263-287.

NÓBREGA. I. C. C. Análise dos compostos voláteis da aguardente de cana por concentração dinâmica do "headspace" e cromatografia gasosa-espectrometria de massas. Boletim da Sociedade Brasileira de Ciência e Tecnologia de Alimentos, v. 23, n. 2, p. 210-216, 2003.

PARAZZI, C. et al. Avaliação e caracterização dos principais compostos químicos da aguardente de cana-de-açúcar envelhecida em tonéis de carvalho (Quercus sp.). Ciência e Tecnologia de Alimentos, v. 28 , n. 1, p. 193-199, 2008. 
PIGGOTT, J. R.; CONNER, J. M. Whiskies. In: LEA, A. G. H.; PIGGOTT, J. R. (Ed.). Fermented beverage production. 2 ed. New York: Klumer Academic/Plenum Publishers, 2003. cap.11, p. 239-262.

PIMENTEL-GOMES, F.; GARCIA, C. H. Estatística aplicada a experimentos agronômicos e florestais: exposição com exemplos e orientações para uso de aplicativos. Piracicaba: FEALQ, 2002. $309 \mathrm{p}$.

PREGNOLATO, W.; PREGNOLATO, N. P. (Coord.). Normas analíticas do Instituto Adolfo Lutz. Métodos químicos e físicos para análise de alimentos. 3 ed. São Paulo: Instituto Adolfo Lutz, 1985. 533 p.

PUECH, J. L. Viellissement du cognac. Sciences des Aliments, v. 4, n. 1, p. 66-80, 1983.
REAZIN, G. H. Chemical mechanisms In whiskey maturation. American Journal of Enology and Viticulture, v. 32, n. 4, p. 283-289, 1981.

SAS - Statistical Analysis System Institute. Sas/Qc software: usage and reference. 2 ed. Cary, 1996. 2 v.

SILVA JÚNIOR., L. S. Avaliação físico-química e sensorial da cachaça durante o envelhecimento em ancorote de carvalho (Quercus sp.) irradiado. Araraquara, 1999. 111p. Dissertação - (Mestrado), Faculdade de Ciências Farmacêuticas, Universidade Estadual Paulista "Júlio de Mesquita Filho".

SINGLETON, V. L. Maturation of wines and spirits: comparison, facts and hypotheses. American Journal of Enology and Viticulture, v. 46, n. 1, p. 98-115, 1995.

SOUZA, M. D. C. A.; DEL MASTRO, N. L. Irradiation of cane sugar spirit. Radiation Physics and Chemistry, v. 57, p. 257-259, 2000. 